\title{
Effect of Total Suspended Particulate Matter in the Air on Inflammation Factors and Apoptotic Markers in Diabetic Rats: The Protective Effect of Insulin and Crocin
}

\author{
Asma Mohammadi ${ }^{1}$, Ali Reza Balizadeh Karami², Seyyed Ali Mard ${ }^{3}$, \\ Gholamreza Goudarzi ${ }^{4}$, Heidar Maleki ${ }^{5}$, Narges Chamkouri ${ }^{1}$, Sara Mobarak ${ }^{1}$, \\ Esmat Radmanesh*1
}

\begin{abstract}
Background: The effect of total suspended particulate matter (TSP) was investigated on the expression of inflammatory and apoptotic factors in diabetic rats, and the effect of crocin and insulin was examined on these factors.

Methods: Fifty-four adult male wistar rats were divided into nine experimental groups: control group, crocin group (received crocin, $50 \mathrm{mg} / \mathrm{kg}$ ), diabetic group (received a single dose of alloxan at $120 \mathrm{mg} / \mathrm{kg}$, IP), TSP group $(5 \mathrm{mg} / \mathrm{kg}$ TSP instilled intratracheally), diabetic-crocin group (received crocin at $50 \mathrm{mg} / \mathrm{kg}$ after the induction of diabetes by alloxan $(120 \mathrm{mg} / \mathrm{kg})$ ), diabetic-insulin group (received regular insulin $(5 \mathrm{U} / \mathrm{kg})$, crocin-TSP group (received crocin at $50 \mathrm{mg} / \mathrm{kg}$, IP, and then $5 \mathrm{mg} / \mathrm{kg}$ TSP was instilled intratracheally), diabetic-TSP-insulin group (after receiving alloxan $(120 \mathrm{mg} / \mathrm{kg}$ ) and instilling TSP $(5 \mathrm{mg} / \mathrm{kg}$, intratracheally), a single dose (5 U/kg) of regular insulin), and diabetic-TSP-crocin group (after receiving alloxan (120 mg/kg) and instilling TSP (5 mg/kg, intratracheally), a single dose of crocin $(50 \mathrm{mg} / \mathrm{kg}, \mathrm{IP}))$. Quantitative real-time PCR was performed to measure the expression of the mRNAs of apoptotic (Bax and $\mathrm{Bcl} 2$ ) and inflammatory mediators (TNF $\alpha, \mathrm{COX} 2$, iNOS/eNOS) in Wistar rats.

Results: In diabetic and TSP groups the inflammatory factors and $\mathrm{BAX} / \mathrm{Bcl} 2$ ratio significantly increased compared to the control group. In diabetic-TSP-insulin and diabetic-TSP-crocin, a significant decrease was observed in the rate of inflammatory factors and $\mathrm{BAX} / \mathrm{Bcl} 2$ ratio.

Conclusions: The results suggested that diabetes and exposure to TSP increase the rate of apoptosis and inflammation, and also demonstrated the anti-apoptotic and anti-inflammation role of insulin and crocin.
\end{abstract}

Keywords: Apoptosis, Crocin, Diabetes, Inflammation, Insulin, TSP.

\section{Introduction}

The number of people with diabetes is expected to increase from 425 million adults in 2017 to 629 million in 2045 (1). Inflammation is a common feature of diabetes (2). There is a direct relationship between inflammation and progression from the prediabetes phase. A high plasma glucose level may modulate the balance of pro-apoptotic and anti-apoptotic $\mathrm{Bcl}$ proteins toward apoptosis (3). The total suspended particulate matter (TSP) is

\section{1: Abadan Faculty of Medical Sciences, Abadan, Iran.}

2: Student Research Committee Abadan Faculty of Medical Sciences, Abadan, Iran.

3: Physiology Research Center, Department of Physiology, Faculty of Medicine, Ahvaz, Jundishapur University of Medical Sciences, Ahvaz, Iran.

4: Air Pollution and Respiratory Diseases Research Center, Ahvaz Jundishapur University of Medical Sciences, Ahvaz, Iran.

5: Faculty of Water Sciences Engineering, ShahidChamran University of Ahvaz, Ahvaz, Iran.

*Corresponding author: Esmat Radmanesh; Tel: +98 9171438307; E-mail: esmatradmanesh33@gmail.com.

Received: 9 Mar, 2021; Accepted: 25 Jun, 2021 
introduced into the atmosphere from the variability of anthropogenic and natural sources (4). Environmental pollution may be a neglected risk factor for diabetes (5). Exposure to particulate matter $(\mathrm{PM})$ has been proved to increase the level of inflammatory cytokines, cyclooxygenase- 2 , iNOS, caspase- 3 , and Bax and decrease the expression of anti-apoptotic protein Bcl-2 (6-15). Antioxidants such as crocin, a natural carotenoid found in Crocus sativus L. (saffron), and Gardenia jasminoides J. Ellis flowers reduce the inflammation and oxidative stress prompted by diabetes and obesity $(16,17)$. The comprehensive antioxidant and anti-inflammatory effects of insulin as a metabolic hormone have been shown with potent effects on glucose and lipid metabolism $(18,19)$. Because of its anti-inflammatory action, insulin can be used as an anti-inflammatory drug (20). Therefore, this study investigated the effect of TSP on the expression of inflammatory factors such as COX2, TNF $\alpha$, and iNOS/eNOS, as well as the expression of $\mathrm{Bax}$ and $\mathrm{Bcl} 2$ in diabetic rats, and examined the effect of crocin and insulin on these factors.

\section{Materials and Methods Studied area}

Abadan is a city in Khuzestan Province in southwestern Iran, located at $30^{\circ} 20^{\prime} 21^{\prime \prime} \mathrm{N}$ $48^{\circ} 18^{\prime} 15^{\prime \prime} \mathrm{E}$. It is one of the few hottest populated places on Earth and experiences many sand and dust storms. The backward trajectory of dust storm and wind direction $\left(\sim 300^{\circ}\right)$ during dust storm in Figure 1 shows that the sources of it are Iraq and Saudi Arabia Pennsylvania. Air pressure was in the lowest level at 9 hours prior to the highest $\mathrm{PM}_{10}$ concentration during the investigated 72-hour. This probably increased wind speed and $\mathrm{PM}_{10}$ concentration into the atmosphere. As a result, dew point, air temperature and relative humidity decreased after the highest $\mathrm{PM}_{10}$ peak (Fig. 1).

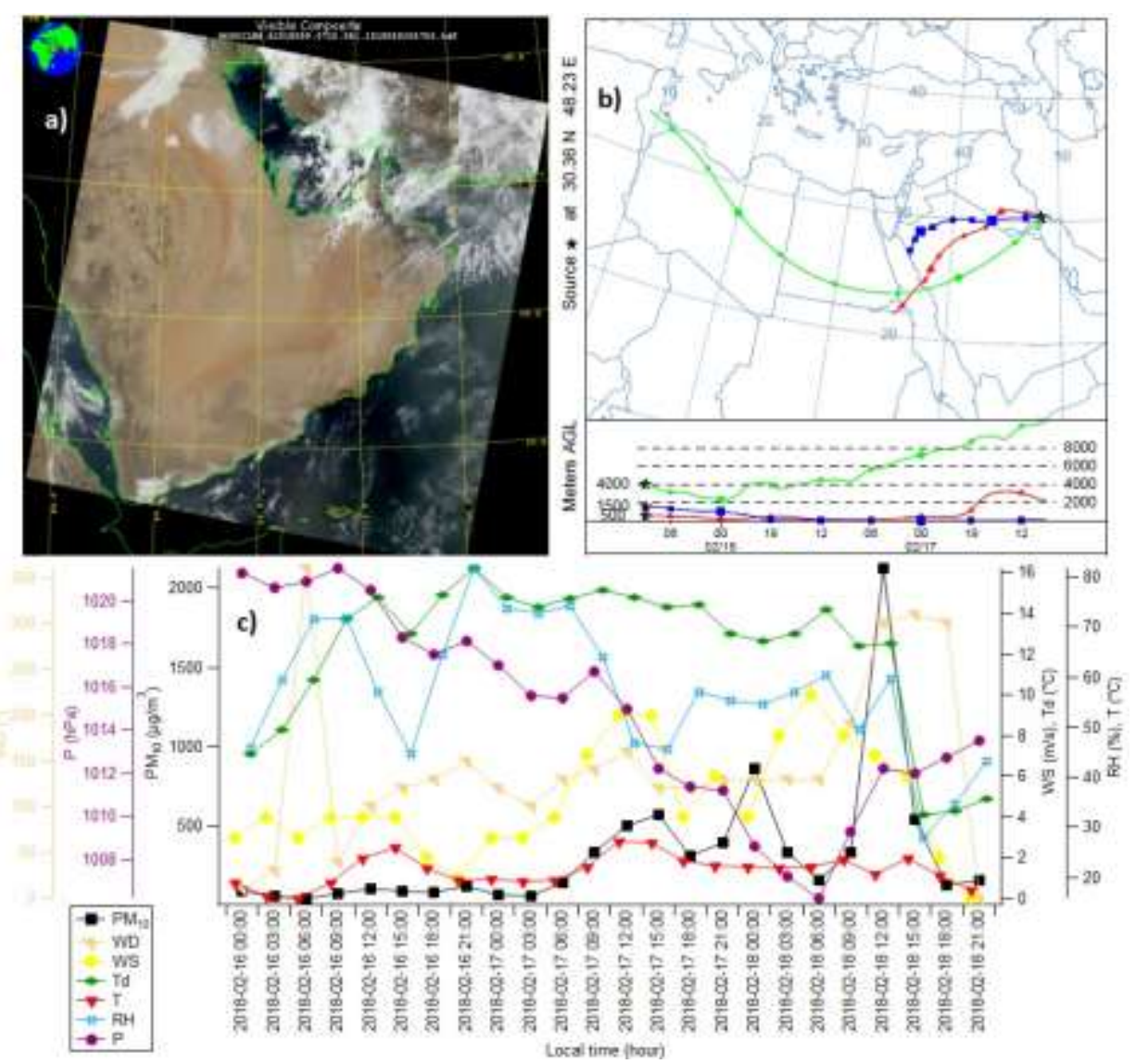

Fig. 1. Properties of the dust storm that occurred on February 182018 (a) 48 hours backward trajectory (b) MODIS imagery from air flow to the region (c) meteorological condition during the dusty day and two preceding days of it (P: Pressure; WD: Wind Direction; T: Temperature; Td: Dew Point; RH: Relative Humidity; WS: Wind Speed). 


\section{Chemicals}

Alloxan monohydrate (Sigma Chemical Company Inc, USA), a High Pure RNA Isolation Kit (Roche Diagnostics GmbH, Germany), and an RT-PCR kit (TAkARA BIO INC, Japan) were employed. Ketamine $\mathrm{HCl}(10 \%)$ and xylazine $(2 \%)$ were obtained from Alfasan Co. (the Netherlands). Crocin sodium was purchased from Sigma-Aldrich Co. (USA), and insulin (LANSULIN) was purchased from Exir Pharmaceutical Company (Iran).

\section{Ethical standard statement}

Animals were treated according to the guidelines of the Animal Care and Use, Ethics Committee of Laboratory Animals, Abadan Faculty of Medical Sciences. Animals were maintained at standard conditions $(50 \%$ humidity, 12-hour dark-light cycle, and $22 \pm 2$ ${ }^{\circ} \mathrm{C}$ temperature), with free access to tap water and standard rat chow diet. Ethical Approval was with IR.ABADANUMS.REC.1395.163 as a reference number.

\section{Instruments, reagents and sample preparation heavy metals concentration}

High-purity concentrated nitric acid $\left(\mathrm{HNO}_{3}\right.$, $65 \%)$, perchloric acid $\left(\mathrm{HClO}_{4}, 70 \%\right)$ and standard solutions of heavy metals including nickel $(\mathrm{Ni})$, mercury $(\mathrm{Hg})$, chromium $(\mathrm{Cr})$, arsenic (As), lead $(\mathrm{Pb})$, and cadmium $(\mathrm{Cd})$ were supplied from Merck (purity higher than 99\%). Ultrapure water was prepared by a Milli-Q system from Millipore (USA). The concentrations of heavy metals such as $\mathrm{Ni}$, $\mathrm{Hg}, \mathrm{Cr}, \mathrm{As}, \mathrm{Pb}$, and $\mathrm{Cd}$ in the soil sample collected on February 16 ${ }^{\text {th }}, 2018$ from Abadan, Iran. Heavy metals have been determined by inductively coupled plasmamass spectrometry (ICP-MS, Agilent 7500, and American). Instrumental conditions of the ICP- MS are: Nebulizer Gas flow rates: 0.8 Lmin ${ }^{-1}$; Auxiliary Gas Flow: $0.8 \mathrm{Lmin}^{-1}$; Plasma, auxiliary, and nebulizer gas: Argon; Plasma Gas Flow: 12.2 $\mathrm{Lmin}^{-1}$; Lens Voltage: 7.25 V; ICP RF Power: $1200 \mathrm{~W}$; Background correction and Sample: Fixed point and aspiration rate: $2 \mathrm{~mL} \min ^{-1}$; RF generator
Power:1200W; Sample uptake time; 260 total (S); Type of detector Solid state: CCD; Type of spray chamber cyclonic: Modified Licht. The samples were analyzed with an ICP-MS by using wavelengths: As $188.98 \mathrm{~nm}, \mathrm{Cd}$ $214.43 \mathrm{~nm}, \mathrm{Cr} 267.71 \mathrm{~nm}, \mathrm{Hg} 184.88 \mathrm{~nm}, \mathrm{Ni}$ $231.64 \mathrm{~nm}$, and $\mathrm{Pb} 220.35 \mathrm{~nm}$.

Acid digestion was used by mixture $\mathrm{HNO}_{3}$ and $\mathrm{HClO}_{4}$. The samples were dried at $105{ }^{\circ} \mathrm{C}$ for $3 \mathrm{~h}$. In the Erlenmeyer, one gram of dried soil sample was poured, and then was added $10 \mathrm{ml}$ of $\mathrm{HNO}_{3} 65 \%$. The new mixture was stored 24 hours in the room temperature. After that, $5 \mathrm{ml}$ of $70 \% \mathrm{HClO}_{4}$ was added to the soil samples. The samples were digested in water bath at $80{ }^{\circ} \mathrm{C}$ for 5 hours. After digestion, the samples placed at ambient temperature to cool and filtered through a Whatman filter $0.45 \mu \mathrm{m}$. The final sample was collected in a volumetric flask and its volume increased to $25 \mathrm{~mL}$ using ultra-pure water (21). After preparation samples, heavy metal concentrations were measurement by using an ICP MS.

\section{Animals and Treatments}

Fifty-four adult male wistar rats with body weight of 200-250 gr were divided into nine experimental groups ( $\mathrm{n}=6$ in each): control group, crocin group: received crocin, $50 \mathrm{mg} / \mathrm{kg}$ (19); crocin was suspended in $0.1 \mathrm{ml}$ of normal saline and administered to the rats via intraperitoneal injection); diabetic group: received a single dose of alloxan at $120 \mathrm{mg} / \mathrm{kg}$, IP (22) to induce diabetes; TSP group: $5 \mathrm{mg} / \mathrm{kg}$ TSP instilled intratracheally; diabetic-crocin group: received crocin at $50 \mathrm{mg} / \mathrm{kg}$ as a single intraperitoneal injection after the induction of diabetes by alloxan $(120 \mathrm{mg} / \mathrm{kg})$; diabeticinsulin: received regular insulin $(5 \mathrm{U} / \mathrm{kg})$ as a single subcutaneous injection after the induction of diabetes by alloxan $(120 \mathrm{mg} / \mathrm{kg})$ (23); crocin-TSP group: received crocin at 50 $\mathrm{mg} / \mathrm{kg}$, IP, and then $5 \mathrm{mg} / \mathrm{kg}$ TSP was instilled intratracheally; diabetic-TSP-insulin group: after receiving alloxan (a single dose of 120 $\mathrm{mg} / \mathrm{kg}$, IP) and instilling TSP $(5 \mathrm{mg} / \mathrm{kg}$, intratracheally), the animals were given a 
single dose $(5 \mathrm{U} / \mathrm{kg})$ of regular insulin by subcutaneous injection; diabetic-TSP-crocin group: after receiving alloxan (a single dose of $120 \mathrm{mg} / \mathrm{kg}$, IP) and instilling TSP (5 mg/kg, intratracheally), the animals were given a single dose of crocin $(50 \mathrm{mg} / \mathrm{kg}$, IP).

\section{Induction of diabetes}

The basal glucose level of the animals was measured before the induction of diabetes. Alloxan monohydrate (Sigma Chemical Company Inc.) was dissolved in sterile normal saline and injected intraperitoneally at a single dose of $120 \mathrm{mg} / \mathrm{kg}$ to five groups of rats. Diabetes was confirmed three days after alloxan injection. Rats with fasting blood sugar $>150 \mathrm{mg}$ /dl were considered as moderate diabetic and were included in the study $(22,24)$.

\section{TSP intratracheal instillation}

Each particle sample (TSP) was suspended in $0.1 \mathrm{ml}$ of saline and mixed. The animals were anesthetized with an IP injection of ketaminexylazine [xylazine $(10 \mathrm{mg} / \mathrm{kg})$ and ketamine (50 mg/kg).

The saline-suspended TPS was instilled into the trachea through the intubation tube. Twenty-four hours later, the animals were anesthetized with an IP injection of ketaminexylazine. Blood samples were collected directly from the heart of the rats $30 \mathrm{~min}$ after crocin administration, transferred into EDTAcontaining tubes, centrifuged at $4000 \mathrm{~g}$ for 10 min to obtain plasma, and stored at $-80{ }^{\circ} \mathrm{C}$ for RNA extraction analysis.

\section{RNA Extraction and cDNA Synthesis}

Total RNA of each sample was extracted from the plasma using the High Pure RNA Isolation Kit (Roche) according to the manufacturer's instructions. The quality and quantity of the RNA were evaluated by ratios of 260/280 using nanodrop spectrophotometry (Nano Drop 2000 Thermo Scientific), and cDNAs were synthesized using a PrimeScript 1st strand cDNA Synthesis Kit (Takara). The cDNA was used as the template in qPCR reactions. Realtime PCR was performed using a LightCycler 96 Detection System (Roche) in a final volume of $20 \mu \mathrm{L}$ reactions. The reagents used in reactions were from the RT-PCR kit (Takara) and included RNase free water and RT-PCR Master Mix. Inflammatory factors and $\mathrm{BAX} / \mathrm{Bcl} 2$ were calculated using the $2-\Delta \Delta \mathrm{Ct}$ method (25). A list of sequences of the PCR primers used for the experiments is given in Table 1 .

Table 1. Sequence of RT-PCR primers for interest and reference genes.

\begin{tabular}{ll}
\hline Oligo name & Sequence $\left(\mathbf{5}^{\prime} \rightarrow \mathbf{3}^{\prime}\right)$ \\
\hline Bcl-2-Forward & TGGTACCTGCAGCTTCTTTC \\
Bcl-2-Reverse & ATCTCCAGTATCCCACTCGTA \\
TNF- $\alpha$-Forward & TGATCCGAGATGTGGAACTG \\
TNF- $\alpha$-Reverse & AACTTCTCCTCCTTGTTGGG \\
eNOS-Forward & GACCCTCACCGATACAACAT \\
eNOS- Reverse & AACTTCTCCTCCTTGTTGGG \\
iNOS-Forward & CGATAAAGGGACAGCGTCA \\
iNOS- Reverse & ACTGGGGGAAACCATTTTGA \\
Cox2 Forward & TCAAACTCAAGTTCGACCCA \\
Cox2 Reverse & GCGATTGGAACATTCCTTCC \\
BAX-Forward & TTTTCCTGGGATGAATGGGG \\
BAX-Reverse & TGAGGTTTATTGGCACCTCC \\
GAPDH- Forward & TCCACCACCCTGTTGCTGTAG \\
GAPDH- Reverse & ACACCCACTCCTCCACCTTTG \\
\hline
\end{tabular}




\section{Statistical analysis}

The data were analyzed using GraphPad Prism 8 and expressed as mean \pm SEM. One-way analysis of variance (ANOVA) followed by LSD was used for comparison tests, and $\mathrm{p}<0.05$ was considered statistically significant.

\section{Results}

\section{Heavy metals concentrations}

The heavy metals in soil sample were analyzed using ICP-MS after acid digestion. In the present work, according above-mentioned conditions the concentrations of some contamination were evaluated in a soil sample. The results of heavy metals concentrations using the proposed methods are summarized in Table 2. In this study the mean concentration of $\mathrm{Cr}$ and $\mathrm{Ni}$ same as and ranged $1.2 \mathrm{ppm}$. According to the results, the concentrations of $\mathrm{Cr}$ and $\mathrm{Ni}$ were lower than the toxicity limits for heavy metals in natural soil.

Table 2. The heavy metals concentration in sample

\begin{tabular}{cc}
\hline Heavy metals & Concentration ppm \\
\hline $\mathrm{As}$ & 0.05 \\
$\mathrm{Cd}$ & 0.10 \\
$\mathrm{Cr}$ & 1.20 \\
$\mathrm{Hg}$ & 0.05 \\
$\mathrm{Ni}$ & 1.20 \\
$\mathrm{~Pb}$ & 4.50 \\
\hline
\end{tabular}

According to the results obtained, the lowest heavy metals content was as and $\mathrm{Hg}$. The mean concentration of as and $\mathrm{Hg}$ obtained 0.05 . The highest concentrations of selected heavy metals were observed in $\mathrm{Pb}$.

The results showed that the concentration of $\mathrm{Cd}$ in the sample amount $0.1 \mathrm{ppm}$, which was below the standard limit. According to the results, the concentrations of six selected heavy metals were lower than the toxicity limits for heavy metals in natural soil. Also, there was no significant deviation from EPA, WHO standards and Europe action level of soil.

\section{Expression of COX2 RNA}

The expression of COX2 mRNA in the diabetic group showed a significant increase compared to the control group $(\mathrm{p}<0.0001)$. In the crocin group, a significant reduction in COX2 levels was observed compared to the control group ( $\mathrm{p}<$ 0.0001). In diabetic groups receiving crocin or insulin, a significant decrease in the COX2 mRNA level was observed compared with the control group. This decrease was higher in the diabetic-crocin group. In the TSP group, a significant increase in COX2 mRNA was observed compared to the control group $(\mathrm{p}<$ 0.0001). In the diabetic-TSP-insulin group, there was a significant decrease in COX2 mRNA compared to the TSP group and diabetic group ( $p<0.0001)$. In diabetic-TSP-crocin group, a significant decrease in COX2 mRNA was observed compared with the diabetic group and TSP group (Fig. 2A) $(\mathrm{p}<0.0001)$.

\section{Expression of TNFa RNA}

The TNF $\alpha$ RNA level in the diabetic group demonstrated a significant increase compared to the control group $(\mathrm{p}<0.0001)$. In the crocin group, a significant decrease in TNF $\alpha$ expression was seen compared to the control group ( $\mathrm{p}<$ 0.0001). In diabetic-crocin group and diabeticinsulin group, a significant reduction in TNF $\alpha$ expression was found compared with the diabetic group $(p<0.0001)$. This decrease was greater the in diabetic-insulin group than the diabetic-crocin group.

In the TSP group, a significant increase in the expression of RNA of $\mathrm{TNF} \alpha$ was observed compared to the control group $(\mathrm{p}<0.0001)$. In the TSP- crocin, there was a significant decrease in TNF $\alpha$ expression compared to the TSP group $(\mathrm{p}<0.0001)$.

In the diabetic-TSP-crocin group, there was a significant decrease in the expression of RNA of TNF $\alpha$ compared to the TSP group and diabetic group ( $p<0.0001)$. In the diabetic-TSP-insulin group, there was a significant decrease in the expression of RNA of TNF $\alpha$ compared to the TSP group and diabetic group ( $p<0.0001)$. This decrease in insulin was more severe than that in crocin, indicating the important role of insulin and crocin in reducing the level of inflammation in diabetics exposed to TSP (Fig. 2B). 


\section{Expression of eNOS RNA}

The eNOS level in the diabetic group showed a significant decrease compared to the control group ( $\mathrm{p}<0.0001)$. In the crocin group, there was a significant decrease in eNOS compared to the control group, but a significant increase compared to the diabetic group $(\mathrm{p}<0.0001)$. In the diabeticinsulin group and diabetic-crocin group, a significant increase was seen compared to the diabetic group $(\mathrm{p}<0.0001)$, which was higher in the diabetic-insulin group. In the TSP group, there was a significant reduction in eNOS expression compared to the control group $(\mathrm{p}<0.0001)$, which was significantly increased due to crocin reception compared to the TSP group $(\mathrm{p}<$ 0.0001). Moreover, there was a significant increase in eNOS expression in diabetic-TSPinsulin group and diabetic-TSP-crocin group compared with the diabetic group $(\mathrm{p}<0.0001)$. This increase was higher in the insulin-receiving group than the crocin-receiving group. There was a significant increase in eNOS expression in diabetic-TSP-insulin group compared with the TSP group $(p<0.0001)$ but no significant relationship was observed in diabetic-TSP-crocin group compared to TSP group (Fig. 3A).

A:

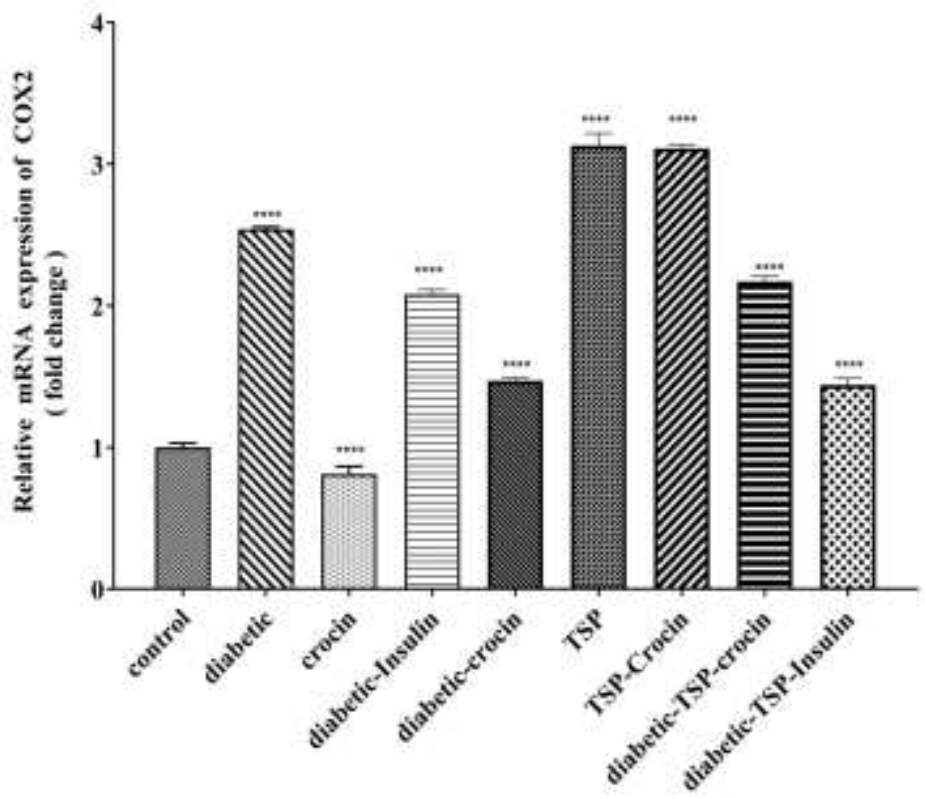

B:

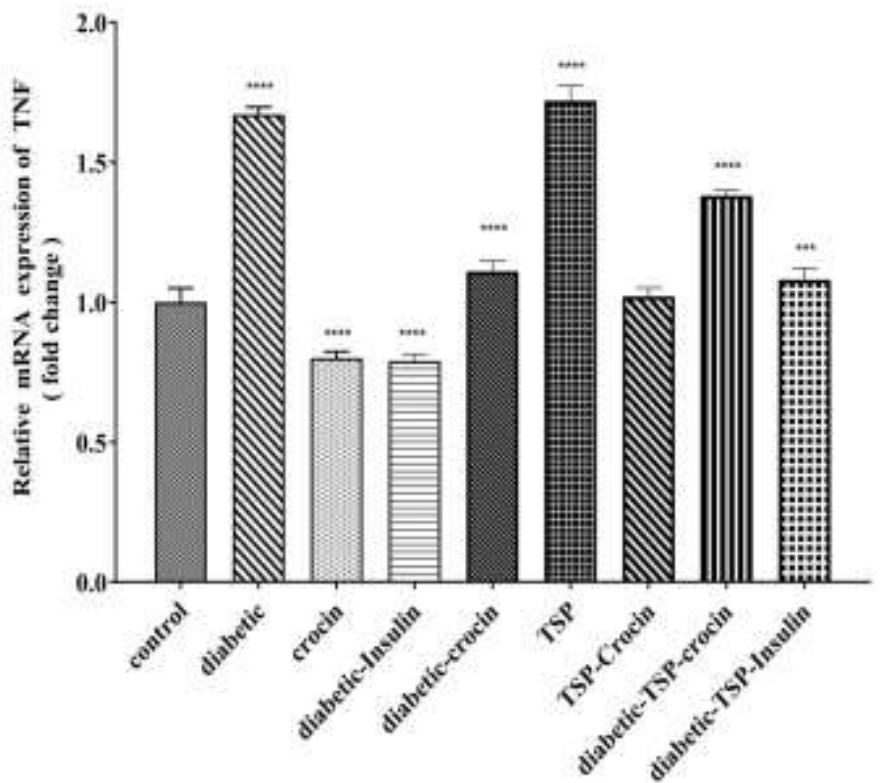

Fig. 2. Effect of crocin, insulin, TSP on A: relative mRNA expression of COX2 (fold change) and B: relative mRNA expression of TNF $\alpha$ (fold change) in diabetic rats. For total test one way ANOVA followed by Fisher s LSD test was used; *** $\mathrm{P}<0.001, * * * * \mathrm{P}<0.0001 \mathrm{Vs}$. control group. 
A:

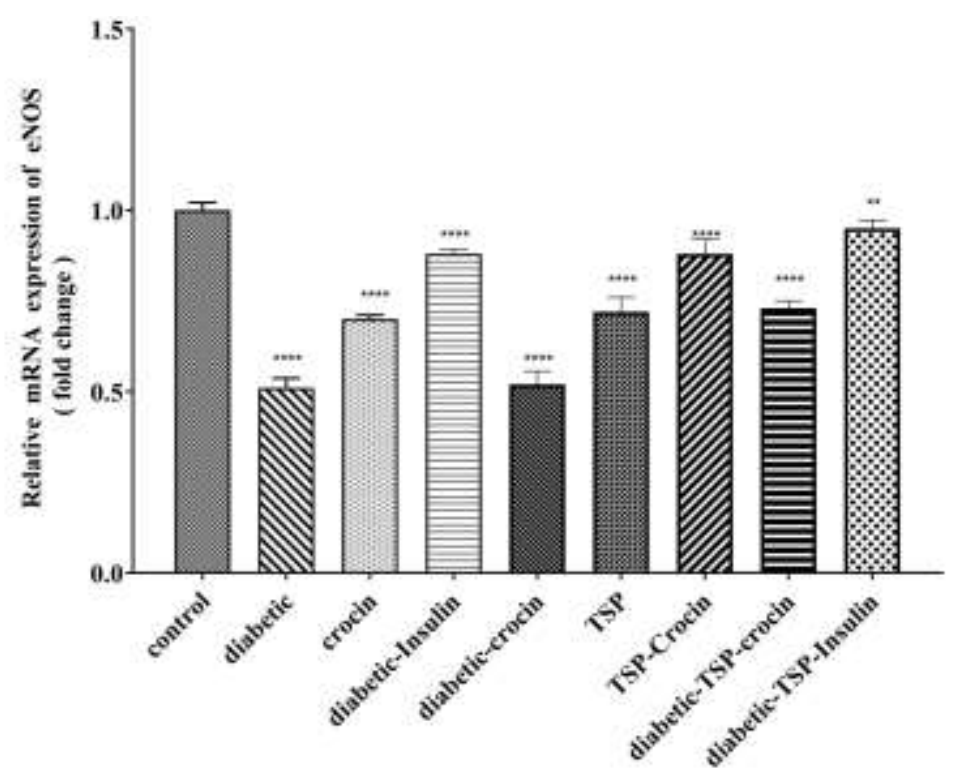

B:

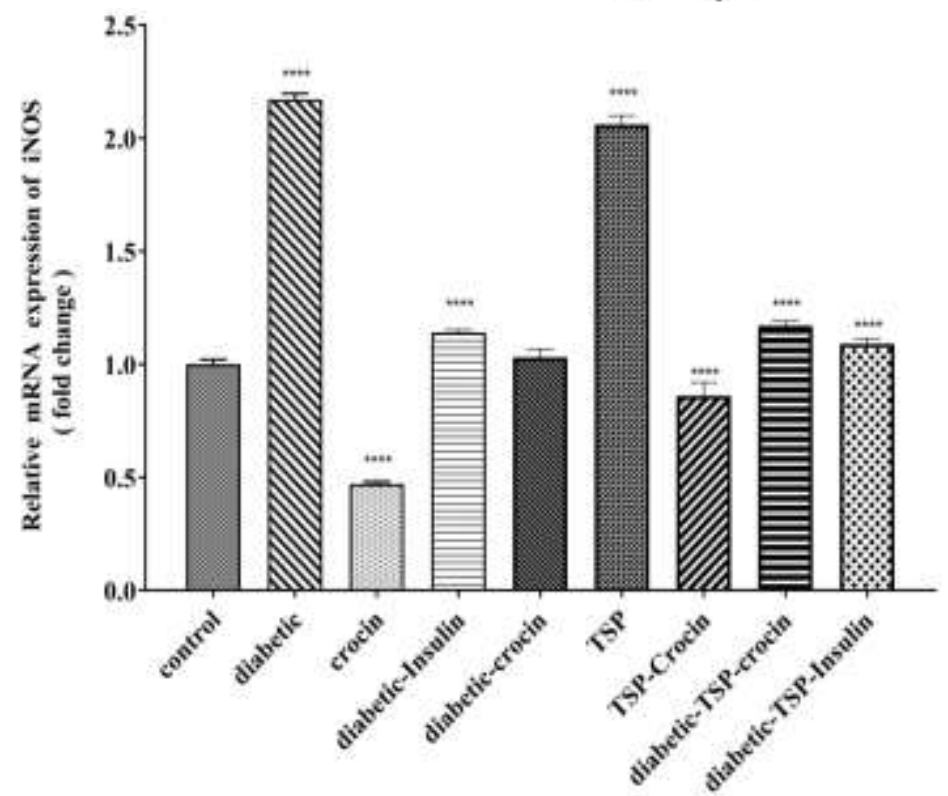

C:

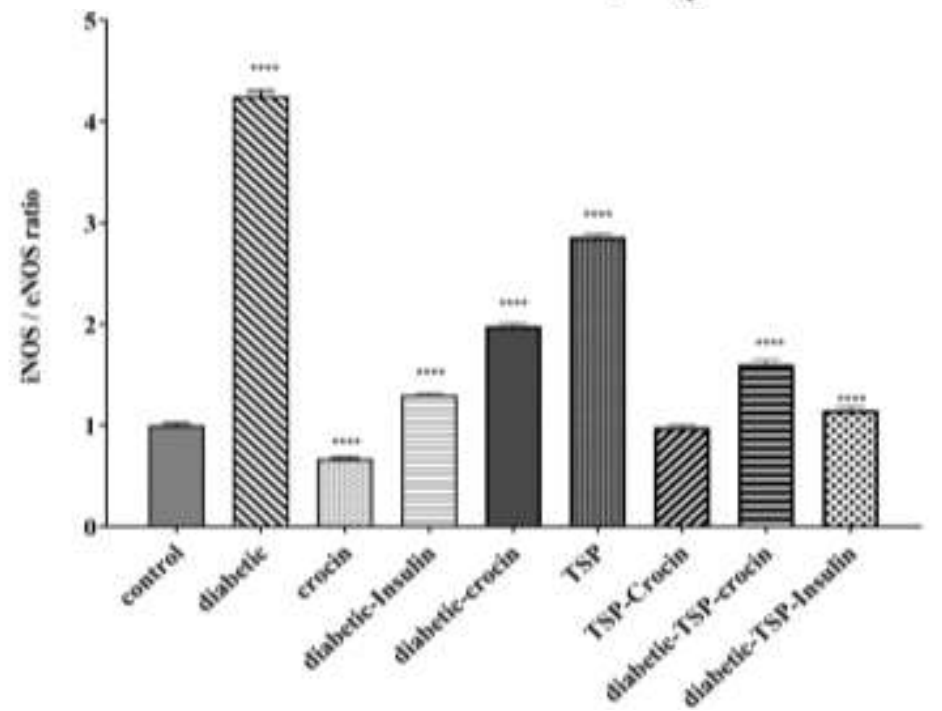

Fig. 3. Effect of crocin, insulin, TSP on A: relative mRNA expression of eNOS (fold change) B: relative mRNA expression of iNOS (fold change) and C: iNOS/eNOS ratio in diabetic rats. For total test one-way ANOVA followed by Fisher s LSD test was used; **** $\mathrm{p}$ $0.001, * * * * \mathrm{p}<0.0001$ Vs. control group. 


\section{Expression of iNOS RNA and iNOS/eNOS Ratio}

There was a significant increase in the expression of iNOS RNA and the ratio of iNOS/eNOS in the diabetic group compared to the control group $(\mathrm{p}<0.0001)$. In the crocin group, there was a significant reduction in the expression of iNOS RNA and the ratio of iNOS/eNOS compared to the control group $(\mathrm{p}<0.0001)$. In the diabetic-crocin group, there was a significant decrease in the ratio of iNOS/eNOS compared to the diabetic group $(\mathrm{p}<0.0001)$. In the TSP group, a significant increase in iNOS and the ratio of iNOS/eNOS was observed compared to the control group ( $p<0.0001)$. In the TSP-crocin, there was a significant decrease in iNOS and the ratio of iNOS/eNOS compared to the TSP-group ( $\mathrm{p}<$ $0.0001)$. In diabetic-TSP-insulin and diabeticTSP-crocin, a significant decrease in iNOS and the ratio of iNOS/eNOS was observed compared with the TSP group and diabetic group ( $p<0.0001)$ (Figs. 3B and 3C).

\section{Expression of Bcl2 RNA}

There was a significant reduction in $\mathrm{Bcl} 2$ expression in the diabetic group compared to the control group $(\mathrm{p}<0.0001)$. In the crocin group, a significant increase in $\mathrm{Bcl} 2$ expression was observed compared to the control group ( $p<0.001$ ). In diabetic-crocin group and diabetic- insulin group, there was a significant increase in $\mathrm{Bcl} 2$ expression compared to the diabetic group $(p<0.0001)$, which was higher in the diabetic-crocin group than diabetic- insulin group. In the group exposed to TSP, there was a significant decrease in $\mathrm{Bcl} 2$ expression compared to the control group ( $\mathrm{p}<0.0001)$. Furthermore, in diabetic-TSP-insulin and diabetic-TSP-crocin, there was a significant increase in $\mathrm{Bcl} 2$ expression compared with the diabetic group and the TSP group $(\mathrm{p}<0.0001)$ (Fig. 4A).

\section{Expression of Bax RNA and Bax /Bcl2 Ratio}

The expression of Bax RNA and the ratio of $\mathrm{Bax} / \mathrm{Bcl} 2$ in the diabetic group showed a significant increase compared to the control group ( $p<0.0001)$. In the crocin group, a significant decrease in the expression of RNA of $\mathrm{Bax}$ and the $\mathrm{Bax} / \mathrm{Bcl} 2$ ratio was seen compared to the control group ( $p<0.0001)$. In the diabetic-crocin group and diabetic-insulin group, a significant decrease in the expression of Bax RNA and the ratio of Bax /Bcl2 was found compared to the diabetic group $(\mathrm{p}<$ 0.0001). In the TSP group, there was a significant increase in the expression of Bax RNA and the ratio of $\mathrm{Bax} / \mathrm{Bcl} 2$ compared to the control group ( $p<0.0001)$, which was significantly reduced in the TSP-crocin group compared to the TSP group. In the diabeticTSP-crocin group, there was a significant decrease in the expression of Bax RNA and the ratio of $\mathrm{Bax} / \mathrm{Bcl} 2$ compared to the TSP-group and diabetic group $(\mathrm{p}<0.0001)$. In the diabeticTSP-insulin, a significant decrease in the expression of Bax RNA and the ratio of Bax /Bcl2 was observed compared to the diabetic group, but no significant change was observed in comparison with the group exposed to TSP (Figs. 4B and 4C).

\section{Discussion}

Our results showed that in diabetic groups, the mRNA expression of the studied inflammatory factors COX2, TNF $\alpha$, iNOS and the ratio of iNOS/eNOS significantly increased compared to the control group, while the gene expression of eNOS significantly decreased. These changes indicated that the rate of inflammation increases in diabetes. These results are in agreement with the findings of Szerafin et al. who reported that COX-2 mRNA expression increased in coronary arterioles in diabetes (26). iNOS is related to tubular damage in renal failure, and the NO increase in diabetes may describe the endothelial dysfunction associated with diabetic complications (27).

In the present study, in the diabetic groups, the expression rate of Bax as an apoptotic factor showed a significant increase compared to the control group, whereas the expression rate of the $\mathrm{Bcl} 2$ factor showed a significant decrease. Accordingly, the ratio of eNOS/iNOS was decreased. Several studies have reported that the expression of Bax is increased in the blood vessels of diabetic patients, and that long hyperglycemia prompts apoptosis in the 
endothelial cells of diabetic ulcers $(28,29)$.

A:

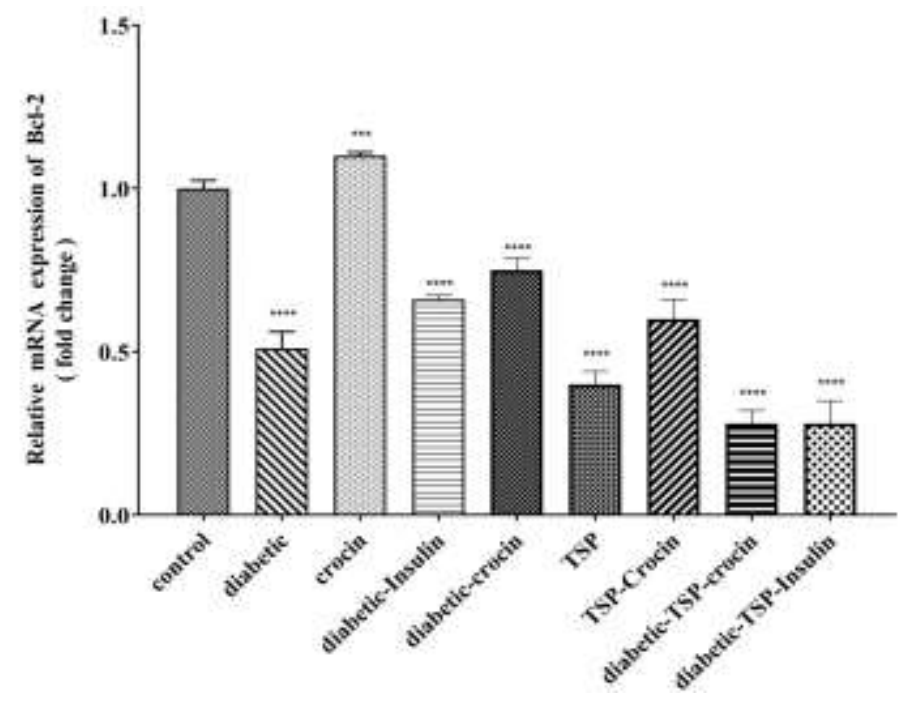

B:

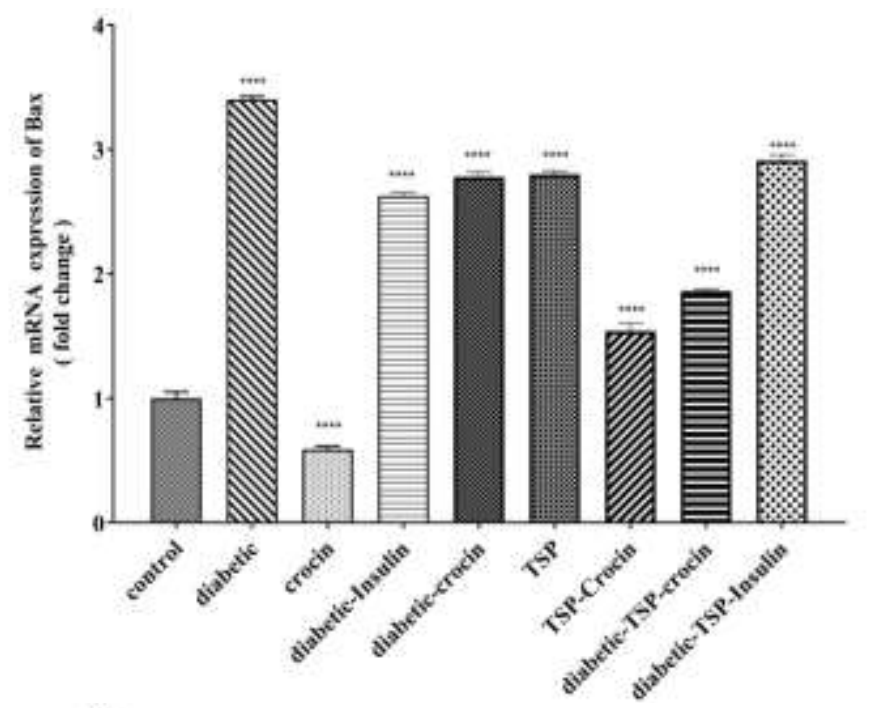

C:

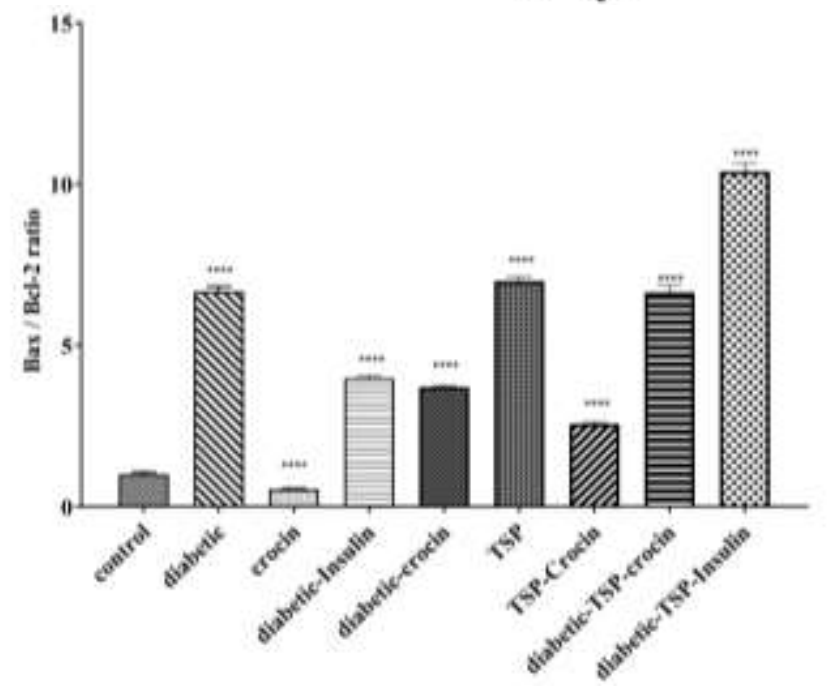

Fig. 4. Effect of crocin, insulin, TSP on A: relative mRNA expression of Bcl2 (fold change), B: relative mRNA expression of Bax (fold change) and C: Bax/Bcl-2 ratio in diabetic rats. For total test one way ANOVA followed by Fisher s LSD test was used; $* * * \mathrm{p}<0.001, * * * * \mathrm{p}<0.0001$ Vs. control group. 
In our study, in the group exposed to TSP, a significant increase was observed in inflammatory factors (COX2, TNF $\alpha$, iNOS, and the ratio of iNOS/eNOS), and a significant decrease was seen in eNOS expression. In the study by Peng et al., high doses of PM increased pro-inflammatory factors significantly (30) and promoted the apoptosis of EPCs in association with increased ROS production and serum TNF$\alpha$ and IL-1 $\beta$ levels (31).The PM10 sample significantly increased the tendency of COX-2, iNOS, and ICAM-1 expression (32).

The results of our study revealed that exposure to TSP reduced $\mathrm{Bcl} 2$ expression and increased Bax expression. In another study, PM up-regulated pro-apoptotic p53, Bad, p21, and Bax and enhanced the mitochondrial localization of Bax and decreases Bcl-2/Bax ratios $(33,34)$.

Based on our findings, in the diabetic groups receiving crocin, a significant decrease in the rate of inflammatory factors was observed, suggesting the effective role of crocin in reducing the rate of inflammation in diabetes. The results of this study demonstrated that crocin improves apoptotic factors (decreases Bax but increases $\mathrm{Bcl} 2$ ) in diabetes, and plays a more effective role than insulin in reducing the expression of Bax mRNA and the ratio of $\mathrm{Bax} / \mathrm{Bcl} 2$. Based on our results, receiving crocin in rats exposed to TSP improves inflammatory factors (decreases the expression of COX, TNF, iNOS, and the ratio of iNOS/eNOS, but increases eNOS). Receiving crocin in rats exposed to TSP improves apoptotic factors as well (decreases Bax but increases Bcl2).

Crocin has been reported to lowers the IL-1 $\beta$ and TNF- $\alpha$ levels, reduces the inflammation in diabetic rats, and inhibits/activates internal and external apoptotic stimulations, which could be effective in diabetes (35).

The results of the present study also showed that insulin can reduce the expression of inflammatory factors as well as the expression of $\mathrm{TNF} \alpha, \mathrm{COX} 2$, and iNOS in diabetes, but increase the expression of eNOS in diabetic groups. This decrease in the insulin-receiving diabetic group was greater than that of the crocin-receiving diabetic group, indicating a stronger anti-inflammatory role of insulin than crocin. Our results also showed that insulin improves apoptotic factors (decreases Bax expression and increases Bcl2) in the diabetic group.

It has been reported that insulin increases Bcl-2 levels and decreases the expression of Bax, indicating its contribution to the prevention of cell death by increasing the expression of antiapoptotic genes and decreasing the expression of pro-apoptotic genes (36). Insulin suppresses endotoxin-induced pro-inflammatory transcription factors and the genes regulated by them, and induces the expression of eNOS, endothelial NO synthase $(37,38)$.

Based on our findings, the increased ratio of $\mathrm{Bax} / \mathrm{Bcl} 2$ resulting from diabetes was improved both by insulin and crocin; in this case, the role of crocin was more effective. The results also showed that in the group exposed to TSP, the $\mathrm{Bax} / \mathrm{Bcl} 2$ ratio showed a significant increase, indicating a significant decrease with crocin. The current findings also revealed that inflammatory factors increased due to diabetes. With insulin or crocin, a significant reduction in inflammatory factors was observed in diabetics, suggesting the strong anti-inflammatory role of crocin and insulin, and the results of this experiment confirmed the stronger anti-inflammatory role of insulin compared to crocin. Moreover, the rate of inflammation increased due to exposure to TSP, and insulin and crocin reduced the rate of inflammation in these groups. The results of this study suggest that diabetes and exposure to TSP may increase the rate of apoptosis and inflammation, and confirm the anti-apoptotic and antiinflammation role of insulin and crocin.

\section{Acknowledgements}

This work was financially supported by Abadan Faculty of Medical Sciences (No. 95U-1065). The authors gratefully acknowledge the NOAA Air Resources Laboratory (ARL) for the provision of the HYSPLIT transport and dispersion model and/or READY website (http://www.ready.noaa.gov) used in this publication. 


\section{References}

1. Laakso M. Biomarkers for type 2 diabetes. Molecular Metabolism. 2019;27:S139-S146.

2. Lontchi-Yimagou E, Sobngwi E, Matsha TE, Kengne AP. Diabetes mellitus and inflammation. Curr Diab Rep. 2013;13(3):435-44.

3. Federici M, Hribal M, Perego L, Ranalli M, Caradonna Z, Perego C, et al. High glucose causes apoptosis in cultured human pancreatic islets of Langerhans: a potential role for regulation of specific Bcl family genes toward an apoptotic cell death program. Diabetes. 2001;50(6):1290-301.

4. David AE, Kesiye IA, Stephen UA, Nimibofa A, Etta BA. Measurement of Total Suspended Particulate Matter (TSP) in an Urban Environment: Yenagoa and Its Environs.

5. Pearson JF, Bachireddy C, Shyamprasad S, Goldfine AB, Brownstein JS. Association between fine particulate matter and diabetes prevalence in the US. Diabetes care. 2010;33(10):2196-2201.

6. Moon D, Park S, Kim S, Kim J, Kim M, Kim $\mathrm{K}$, et al. Altered proinflammatory cytokines and $\mathrm{m} 1$ polarization induced by pm2. 5 in alveolar macrophages. Applied Ecology And Environmental Research. 2018;16(6):7699-7712. 7. Tsai D-H, Amyai N, Marques-Vidal P, Wang J-L, Riediker M, Mooser V, et al. Effects of particulate matter on inflammatory markers in the general adult population. Part Fibre Toxicol. 2012;9:24.

8. Pope III CA, Bhatnagar A, McCracken JP, Abplanalp W, Conklin DJ, O'Toole T. Exposure to fine particulate air pollution is associated with endothelial injury and systemic inflammation. Circ Res. 2016;119(11):1204-1214.

9. Liu X, Zhang Y, Yang X. PM 2.5 induced neurodegenerative-like changes in mice and the antagonistic effects of vitamin E. Toxicol Res (Camb). 2019;8(2):172-179.

10. Guo Z, Hong Z, Dong W, Deng C, Zhao R, $\mathrm{Xu}$ J, et al. PM2.5-induced oxidative stress and mitochondrial damage in the nasal mucosa of rats. Int J Environ Res Public Health. 2017;14(2):134. 11. Villarreal-Calderon R, Reed W, PalaciosMoreno J, Keefe S, Herritt L, Brooks D, et al. Urban air pollution produces up-regulation of myocardial inflammatory genes and dark chocolate provides cardioprotection. Exp Toxicol Pathol. 2012;64(4):297-306.

12. Lee C-W, Lin Z-C, Hu SC-S, Chiang Y-C, Hsu L-F, Lin Y-C, et al. Urban particulate matter down-regulates filaggrin via $\mathrm{COX} 2$ expression/PGE2 production leading to skin barrier dysfunction. Sci Rep. 2016;6:27995.

13. Long M-H, Zhu X-M, Wang Q, Chen Y, Gan $\mathrm{X}-\mathrm{D}, \mathrm{Li}$ F, et al. PM2.5 exposure induces vascular dysfunction via NO generated by iNOS in lung of ApoE-/-mouse. Int J Biol Sci. 2020;16(1):49-60. 14. Dou C, Zhang J, Qi C. Cooking oil fumederived PM 2.5 induces apoptosis in A549 cells and MAPK/NF-KB/STAT1 pathway activation. Environ Sci Pollut Res Int. 2018;25(10):99409948.

15. Ru Q, Xiong Q, Chen L, Tian X, Yue K, Ma $\mathrm{B}$, et al. Lipopolysaccharide accelerates fine particulate matter-induced cell apoptosis in human lung bronchial epithelial cells. Int J Occup Med Environ Health. 2018;31(2):173-183.

16. Pham TQ, Cormier F, Farnworth E, Tong VH, Van Calsteren M-R. Antioxidant properties of crocin from Gardenia jasminoides Ellis and study of the reactions of crocin with linoleic acid and crocin with oxygen. J Agric Food Chem. 2000;48(5):1455-61.

17. Sanchez AM, Carmona M, Jaren-Galan M, Minguez Mosquera MI, Alonso GL. Picrocrocin kinetics in aqueous saffron spice extracts (Crocus sativus L.) upon thermal treatment. J Agric Food Chem. 2011;59(1):249-55.

18. Dandona P, Chaudhuri A, Ghanim H, Mohanty P. Insulin as an anti-inflammatory and antiatherogenic modulator. J Am Coll Cardiol. 2009;53(5 Supplement):S14-S20.

19. Margaritis I, Angelopoulou K, Lavrentiadou S, Mavrovouniotis IC, Tsantarliotou M, Taitzoglou I, et al. Effect of crocin on antioxidant gene expression, fibrinolytic parameters, redox status and blood biochemistry in nicotinamidestreptozotocin-induced diabetic rats. J Biol Res (Thessalon). 2020;27:4.

20. Dandona P, Chaudhuri A, Mohanty P, Ghanim H. Anti-inflammatory effects of insulin. Curr Opin Clin Nutr Metab Care. 2007;10(4):511-7. 
21. Carter MR, Gregorich, EG. (Ed.). Soil Sampling and Methods of Analysis: CRC Press; 2007.

22. Lachin T, Reza H. Anti diabetic effect of cherries in alloxan induced diabetic rats. Recent Pat Endocr Metab Immune Drug Discov. 2012;6(1):67-72.

23. Zheng J, Zhang G, Lu Y, Fang F, He J, Li N, et al. Effect of pulmonary surfactant and phospholipid hexadecanol tyloxapol on recombinant human-insulin absorption from intratracheally administered dry powders in diabetic rats. Chem Pharm Bull (Tokyo). 2010;58(12):1612-6.

24. Omabe M, Nwudele C, Omabe KN, Okorocha AE. Anion gap toxicity in alloxan induced type 2 diabetic rats treated with antidiabetic noncytotoxic bioactive compounds of ethanolic extract of Moringa oleifera. J Toxicol. 2014; 2014:406242.

25. Jamaati H, Bahrami N, Daustany M, Tabarsi $\mathrm{P}$, Farzanegan $\mathrm{B}$, Hashemian $\mathrm{S} \mathrm{M}$ et al. Investigating PIK3R3 and ATp2A1 Genes Expressions in Ventilator-Associated Pneumonia Patients Admitted to the Intensive Care Unit of Masih Daneshvari Hospital in 2016. Rep Biochem Mol Biol. 2018;6(2):118-124.

26. Szerafin T, Erdei N, Fülöp T, Pasztor ET, Édes In, Koller A, et al. Increased cyclooxygenase-2 expression and prostaglandinmediated dilation in coronary arterioles of patients with diabetes mellitus. Circ Res. 2006;99(5):e12-7.

27. Aly MI, Abdalla MN, El Akad MH, ElSheikh SA, Yousief EM. Role of iNOS and eNOS expression in a group of Egyptian diabetic and nondiabetic nephropathy patients. The Egyptian Journal of Internal Medicine. 2013;25(1):33-36.

28. Hasnan J, Yusoff M, Damitri T, Faridah A, Adenan A, Norbaini T. Relationship between apoptotic markers (Bax and Bcl-2) and biochemical markers in type 2 diabetes mellitus. Singapore Med J. 2010;51(1):50-5.

29. Koh P-O. Streptozotocin-induced diabetes increases apoptosis through JNK phosphorylation and Bax activation in rat testes. J Vet Med Sci. 2007;69(9):969-71.
30. Tamagawa E, Bai N, Morimoto K, Gray C, Mui T, Yatera K, et al. Particulate matter exposure induces persistent lung inflammation and endothelial dysfunction. Am J Physiol Lung Cell Mol Physiol. 2008;295(1):L79-L85.

31. Cui Y, Xie X, Jia F, He J, Li Z, Fu M, et al. Ambient fine particulate matter induces apoptosis of endothelial progenitor cells through reactive oxygen species formation. Cell Physiol Biochem. 2015;35(1):353-63.

32. Guo L, Li B, Miao J-j, Yun Y, Li G-k, Sang N. Seasonal variation in air particulate matter (PM10) exposure-induced ischemia-like injuries in the rat brain. Chem Res Toxicol. 2015;28(3):431-9.

33. Kamdar O, Le W, Zhang J, Ghio A, Rosen G, Upadhyay D. Air pollution induces enhanced mitochondrial oxidative stress in cystic fibrosis airway epithelium. FEBS Lett. 2008;582(2526):3601-3606.

34. Zheng X, Wang X, Wang T, Zhang H, Wu H, Zhang $\mathrm{C}$, et al. Gestational exposure to particulate matter 2.5 (PM2.5) leads to spatial memory dysfunction and neurodevelopmental impairment in hippocampus of mice offspring. Front Neurosci. 2019;12:1000.

35. Hazman Ö, Aksoy L, Büyükben A. Effects of crocin on experimental obesity and type- 2 diabetes. Turk J Med Sci. 2016;46(5):1593-1602. 36. Soleymaninejad M, Joursaraei SG, Feizi F, Jafari Anarkooli I. The effects of lycopene and insulin on histological changes and the expression level of Bcl-2 family genes in the hippocampus of streptozotocin-induced diabetic rats. J Diabetes Res. 2017;2017:4650939.

37. Aljada A, Dandona P. Effect of insulin on human aortic endothelial nitric oxide synthase. Metabolism. 2000;49(2):147-50.

38. Jeschke MG, Klein D, Bolder U, Einspanier R. Insulin attenuates the systemic inflammatory response in endotoxemic rats. Endocrinology. 2004;145(9):4084-93. 